\title{
Endoscopic removal of an eroded silicone ring after banded sleeve gastrectomy using argon plasma coagulation
}

A 42-year-old woman, who had undergone banded sleeve gastrectomy 9 months previously, presented to us with abdominal pain and vomiting after meals for the preceding 1 month. Upper gastrointestinal endoscopy (Olympus gastroscope series 190) revealed erosion of the silicone ring in the stomach ( $\triangleright$ Fig.1a).
Removal of the eroded silicone ring was attempted using a therapeutic scope (Olympus gastroscope series 180 2T) ( $\triangleright$ Video 1). We grasped the ring using rat-tooth biopsy forceps and initially used endoscopic scissors to cut the ring ( $>$ Fig.1 b); however, we failed to remove it. We subsequently rotated the ring

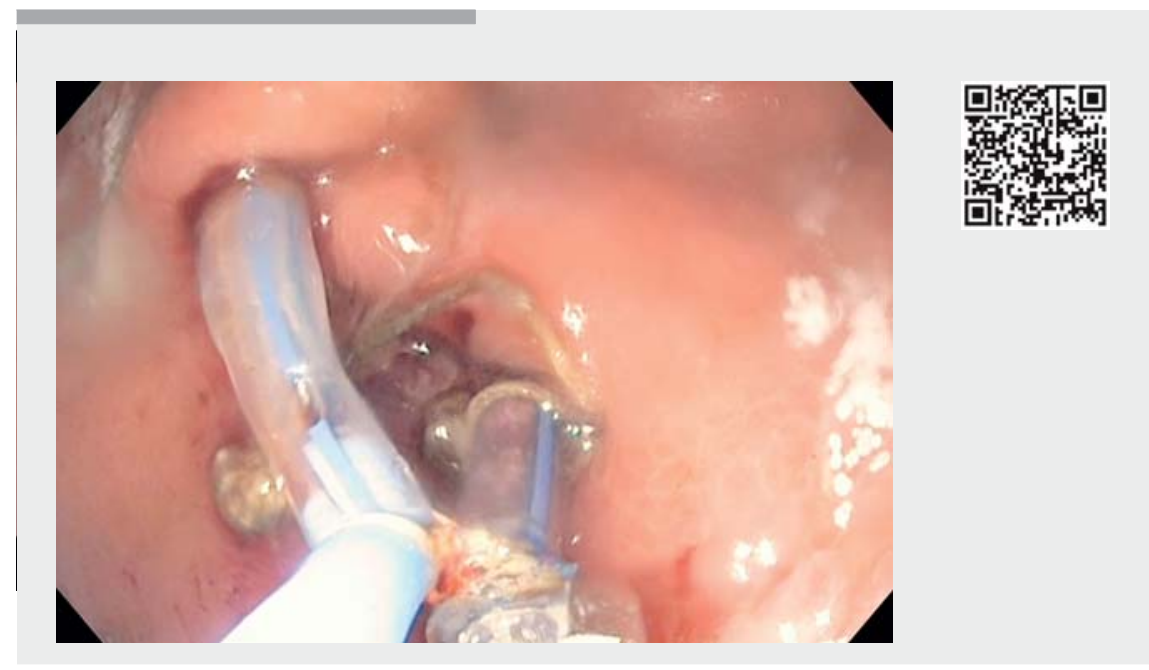

Video 1 Video showing endoscopic removal of an eroded silicone ring using argon plasma coagulation after failure of removal with endoscopic scissors.

using two forceps to expose the site of the suture. We then cut the suture using argon plasma coagulation (APC; $60 \mathrm{~W}$, flow $2 \mathrm{~L} / \mathrm{min}$ ) ( $\triangleright$ Fig. $\mathbf{~ c}$ ) and removed the silicone ring ( $\triangleright$ Fig. 2 ). Radiographic images using oral Gastrografin on postoperative day 1 showed no evidence of leakage ( $>$ Fig. 3 ).

Ring erosion is a rare complication seen in $0-7 \%$ of patients undergoing banded bariatric surgery [1]. When eroded, a ring can be removed endoscopically using scissors to cut the ring [2]; however, in this case we were unable to cut the ring using endoscopic scissors and subsequently used APC to fulgurate the ring and remove it. The case shows that endoscopic scissors can fail in the removal of a post-bariatric eroded silicone ring, but that APC can be used to fulgurate the ring and remove it endoscopically, thereby circumventing the need for surgery.

Endoscopy_UCTN_Code_TTT_1AO_2AL

\section{Competing interests}

\section{None}

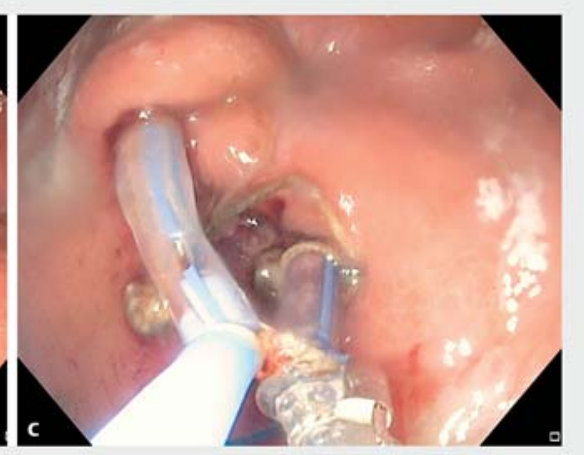

- Fig. 1 Endoscopic views showing: a an eroded silicone ring being held by rat-tooth forceps in the stomach of a patient who had previously undergone banded sleeve gastrectomy; $\mathbf{b}$ endoscopic scissors being used to attempt to cut the silicone ring; $\mathbf{c}$ argon plasma coagulation being used to fulgurate the eroded ring. 


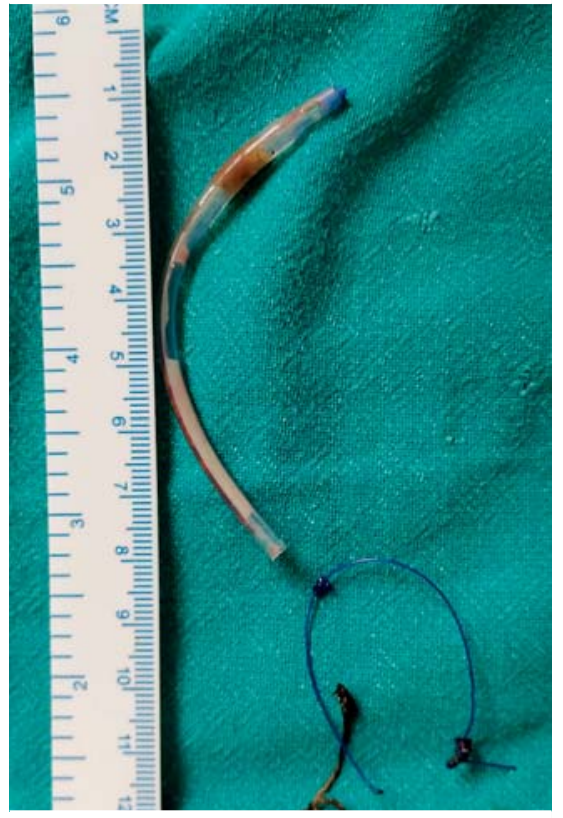

- Fig. 2 Photograph of the eroded silicone ring after its removal.

The authors

\section{Saransh Jain, Mohit Bhandari}

Department of Bariatric Surgery, Mohak

Bariatric and Robotics, Indore, India

\section{Corresponding author}

\section{Mohit Bhandari, MS}

Mohak Bariatrics and Robotics, Indore, India drmohitbhandari@gmail.com
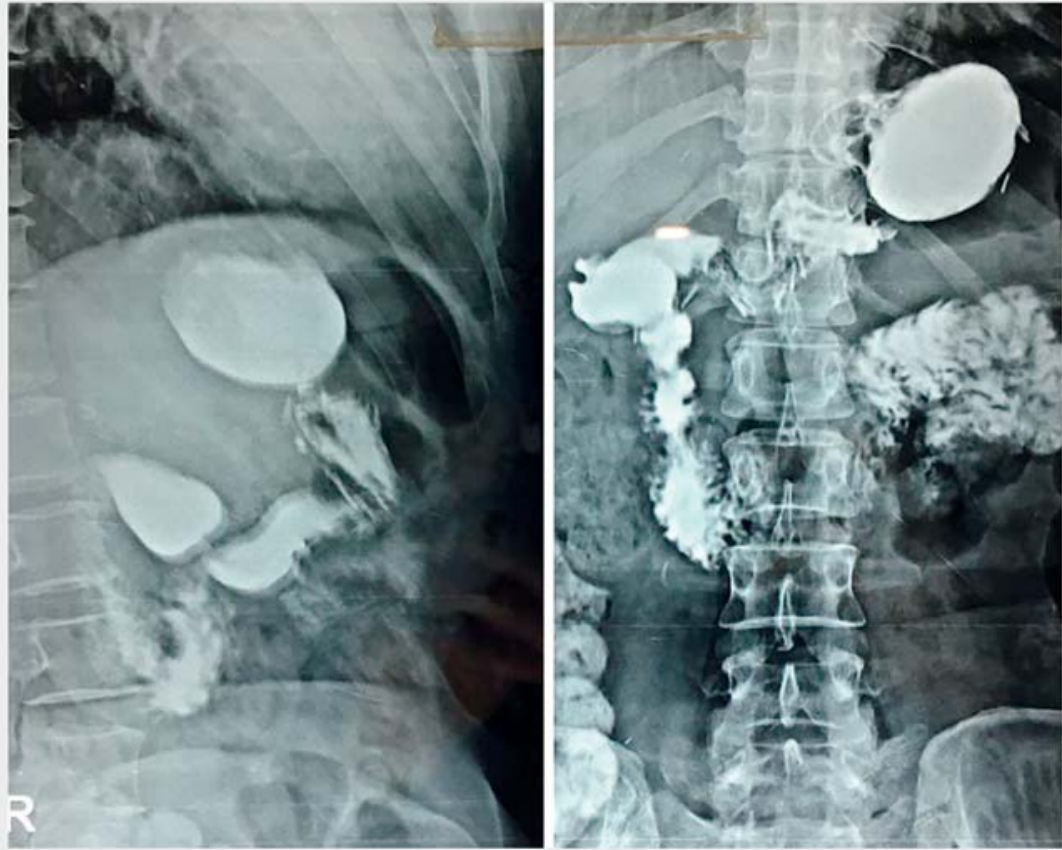

- Fig. 3 Radiographic images using oral Gastrografin taken on post-operative day 1 showing no evidence of leakage.

\section{References}

[1] Magouliotis DE, Tasiopoulou VS, Svokos KA et al. Banded vs. non-banded Roux-en-Y gastric bypass for morbid obesity: a systematic review and meta-analysis. Clin Obes 2018; 8: 424-433

[2] Shehab H, Gawdat K. Endoscopic management of eroded bands following bandedgastric bypass (with video). Obes Surg 2017; 27: $1804-1808$

\section{Bibliography}

DOI https://doi.org/10.1055/a-0889-7394

Published online: 4.6.2019

Endoscopy 2019; 51: E312-E313

(c) Georg Thieme Verlag KG

Stuttgart · New York

ISSN 0013-726X

\section{ENDOSCOPY E-VIDEOS}

https://eref.thieme.de/e-videos

口回 Endoscopy E-Videos is a free access online section, reporting 回: on interesting cases and new techniques in gastroenterological endoscopy. All papers include a high quality video and all contributions are freely accessible online.

This section has its own submission website at https://mc.manuscriptcentral.com/e-videos 